\title{
A IMPUNIBILIDADE DA PORNOGRAFIA INFANTIL NO ÂMBITO DA INTERNET
}

\section{ARTIGO ORIGINAL}

BATISTA, Sara Cristina ${ }^{1}$, TARREGA, Maria Cristina Vidotte Blanco ${ }^{2}$

BATISTA, Sara Cristina. TARREGA, Maria Cristina Vidotte Blanco. A impunibilidade da pornografia infantil no âmbito da internet. Revista Científica Multidisciplinar Núcleo do Conhecimento. Ano. 07, Ed. 01, Vol. 06, pp. 75-89. Janeiro de 2022. ISSN: 2448-0959, Link de acesso: https://www.nucleodoconhecimento.com.br/lei/pornografia-infantil

\section{RESUMO}

Este artigo trata-se de uma análise acerca das dificuldades impostas ao combate a pornografia infantil no ambiente virtual em razão das facilidades ofertadas pelo cyber space. Examinou-se pontualmente os obstáculos práticos enfrentados pelos órgãos de investigação, como a falta de preparo e de tecnologias sensíveis e ainda, as lacunas legais que dificultam a punição de indivíduos envolvidos em tais práticas delitivas. A pergunta norteadora do tema é a seguinte: Quais medidas podem ser tomadas a fim de combater a impunibilidade dos crimes sexuais virtuais contra crianças e adolescentes, tendo em vista, a defasagem de instrumentos investigatórios e jurídicos adequados? O objetivo geral é compreender as razões da impunibilidade e definir quais ações contribuirão para a solução da problemática. Como metodologia, os estudos sobre a pedofilia na internet foram realizados em cima de minuciosa

${ }^{1}$ Pós-Graduada em Direito Ambiental, pela Faculdade Mantenense dos Vales Gerais - Intervale MG; Pós-Graduada em Direito Administrativo-econômico, pela Faculdade Mantenense dos Vales Gerais - Intervale MG; Graduada em Direito, pela Pontifícia Universidade Católica de Goiás - PUC GO. ORCID: 0000-0003-2760-0519

2 Orientador. ORCID: 0000-0002-4805-4345

RC: 105859

Disponível em: https://www.nucleodoconhecimento.com.br/lei/pornografia-infantil 
pesquisa, guiada sobretudo por doutrinas e leis, além da exposição de dados estatísticos. Por fim, apesar das dificuldades destacadas, concluiu-se que é possível solucionar o problema da impunibilidade com ações integradas e harmonizadas, seja por meio de atualização legislativa, bem como, por intermédio de incentivos governamentais no preparo de equipes específicas e de instrumentos tecnológicos adequados para a investigação dessas práticas delitivas virtuais.

Palavras-chave: pornografia infantil, Internet, Impunibilidade.

\section{INTRODUÇÃO}

O tema deste artigo é: A Impunibilidade da Pornografia Infantil no Âmbito da Internet. Sendo de análise importante, tendo em vista que a internet, atualmente, é o principal mecanismo de veiculação, de difusão e de compartilhamento de informações do mundo e, apesar dos inúmeros benefícios trazidos pela Web, difundiu-se, também, a criminalidade, favorecida pelo anonimato e pela viralização rápida de informações na rede mundial de computadores.

A questão problema deste trabalho é: Quais medidas podem ser tomadas a fim de combater a impunibilidade dos crimes sexuais virtuais contra crianças e adolescentes, tendo em vista, a defasagem de instrumentos investigatórios e jurídicos adequados? Dessa maneira, busca-se responder quais ações serão capazes de combater a desatualização legislativa e o atraso tecnológico dos órgãos responsáveis pelo procedimento investigatório em face das facilidades ofertadas pelo ambiente virtual.

O objetivo geral é compreender as razões da impunibilidade e definir quais ações contribuirão para a solução da problemática. Os objetivos específicos visam analisar a fundo os dispositivos legais relacionados ao tema, principalmente os artigos 241, 241-A, 241-B, 241-C, 241-D e 241-E do Estatuto das Crianças e do Adolescentes (ECA), que tratam dos crimes contra liberdade sexual no ambiente virtual e seus desdobramentos.

RC: 105859

Disponível em: https://www.nucleodoconhecimento.com.br/lei/pornografia-infantil 
Como metodologia, os estudos sobre a impunibilidade da pornografia infantil na internet foram realizados em cima de pesquisa bibliográfica, norteada, sobretudo, por doutrinas de juristas brasileiros, por legislações relacionadas ao assunto e, ainda, pela exposição de dados estatísticos confiáveis que denunciam a realidade e a importância do tema.

Inobstante os desafios apresentados pela questão norteadora, concluiu-se que diversas medidas podem contribuir para a solução da questão, como a atualização legislativa eficiente, a integração dos órgãos de investigação e ainda, a estruturação e a capacitação tecnológica adequadas.

\section{CONCEITO E PRECEDENTE HISTÓRICO DA PEDOFILIA}

\subsection{EVOLUÇÃO HISTÓRICA DA PEDOFILIA}

A pedofilia e a exploração sexual de impúrberes são uma prática milenar e que há muito tempo faz parte da humanidade em diversas culturas e contextos sociais, fato é que desde sempre crianças e adolescentes no mundo são submetidos, em razão de sua condição, a situações de abuso sexual (HISGAIL, 2007, p. 13, 14).

A pedofilia e a exploração sexual de crianças e adolescentes são fenômenos que possuem particularidades históricas, culturais, econômicas, raciais e étnicas. Hisgail (2007, p. 13, 14), relata a evolução da sexualidade infantil em diversas culturas e épocas, até enfim, surgirem os primeiros resquícios de respeito a liberdade e a dignidade sexual infantil:

Os registros etnográficos e os documentos antigos sobre a infância atestam que o infanticídio ocorria em sociedades incestuosas por meio de sacrifícios de crianças entre 400 a 200 a.C. O sagrado e o profano mesclavam-se nas tradições e ritos da Nova Guiné, dos Incas, e de outros grupos sociais. [...] No Zoroastrismo, o matrimônio entre irmãos, pais e filhos era corrente, enquanto nos costumes indianos e chineses a masturbação exercida na criança funcionava para adormecê-la e apaziguar o ardor libidinal do adulto. Na antiga Grécia, o sexo dos efebos e as aventuras homoeróticas dos adultos eram consideradas como um rito de passagem da infância a adolescência. [...] na idade

RC: 105859

Disponível em: https://www.nucleodoconhecimento.com.br/lei/pornografia-infantil 
média as ligações libidinais entre filhos e pais faziam parte do cotidiano familiar até atingirem a idade de seis ou sete anos quando eram afastados das intimidades sexuais dos genitores. A criança pequena equivalia a uma fonte de distração e convivia no meio dos adultos de maneira precoce. [...] O habito de entregá-las a famílias estranhas vem do século quinze e consistia em fazê-las servidoras domésticas e aprendizes de regras sociais e religiosas. No fim do século dezessete, a aprendizagem feita por um tutor ou chefe de família foi substituída pela escola, por uma pedagogia corretiva e punitiva baseada na moralidade daquele período. A pedagogia dos séculos dezenove e vinte frutificou os ideais dos "reformadores católicos ou protestantes ligados à igreja, as leis ou ao Estado". Os pais, empenhados em proteger os filhos, transformarão a afeição na necessidade de educar e de atender as demandas dos estudos. [...]

É fato que a pedofilia nunca deixou de existir e de ser praticada em todo mundo, no entanto, após surgimento dos primeiros vestígios de educação e respeito as crianças ao fim da Idade Média, por volta do século XVI para o XVII, iniciou-se também a repressão à prática pedofilia, deixando a mesma de ser comum e passando na maior do mundo a ser criminalizada (LOUREIRO E SILVA, 2019, p. 1).

No Brasil, a atual Carta Magna inovou ao se preocupar em assegurar as crianças e adolescentes direitos e garantias intangíveis. Em seu artigo 227, caput, a Constituição Federal do Brasil (1988, p. 1) traçou direitos e garantias ao dizer que "é dever da família, da sociedade e do Estado assegurar à criança, ao adolescente e ao jovem, com absoluta prioridade, o direito à vida, à saúde, à alimentação [...]".

O doutrinador Lenza (2017, p 1.423) informa que "a Constituição de 1988 avança na proteção à criança, ao adolescente e ao jovem, fixando diversos direitos fundamentais". Leciona ainda (2017, p. 1426) acerca do art. 227 da CF. In verbis:

É dever da família, da sociedade e do Estado, colocando-os a salvo de toda forma de negligência, discriminação, exploração, violência, crueldade e opressão, assegurar a criança, ao adolescente e ao jovem, com absoluta prioridade, o direito.

Mais adiante na década de noventa, embasado na Constituição Federal de 1988, surge o Estatuto da Criança e do Adolescente (ECA - Lei 8.069/90) no intuito de 
regularizar, tipificar e completar as lacunas da nova demanda de direitos dos vulneráveis.

Já no $1^{\circ}$ artigo, o ECA (1990, p. 1) diz "esta lei dispõe sobre a proteção integral à criança e ao adolescente". No entanto é a partir do artigo 225 que trata pormenorizadamente dos crimes contra estes, dizendo "este capítulo dispõe sobre crimes praticados contra a criança e o adolescente, por ação ou omissão, sem prejuízo do disposto na legislação penal".

Por conseguinte, o artigo 240 e seguintes pontua especificamente a problemática em torno da pedofilia e sua criminalização. Nucci $(2017$, p. 106) certifica:

A reforma introduzida pela lei 11.829 , de 25 de novembro de 2008 , no Estatuto da Criança e do Adolescente, tem por finalidade acompanhar os passos da modernidade e da tecnologia, está cada vez mais disseminada entre os jovens, com livre e fácil acesso, não somente no Brasil, mas também em outros países.

No tocante a reforma mencionada e promovida pela lei $11.829 / 08$ no ECA, diz ainda (NUCCl, 2017, p. 107):

O Estatuto da Criança e do Adolescente, em visão mais particularizada, tem pôr fim a punição, no cenário da liberdade sexual, de agentes que envolvam crianças e adolescentes, em práticas sexuais, com o objetivo de satisfação da lascívia, em grande parte dos casos, porém sem haver o contato sexual direto, ao menos necessariamente.

Embora tenha ocorrido a ascensão da proteção ao menor, conforme supracitado, inclusive no Brasil, a Pedofilia, mesmo já criminalizada, continuou ocorrendo silenciosamente, de modo que quem a prática por vezes não é descoberto. A estudiosa Hisgail (2007, p. 17) noticia como a Pedofilia era praticada no fim do século $X X$ e relata que:

Na década de noventa, a exploração comercial e sexual infantil vitimou milhões de crianças e adolescentes no mundo. Devido à pobreza, o desemprego, a desestruturação familiar e a banalização da sexualidade, a Pedofilia ressurge na calada da vida cotidiana como uma perversão sexual, a ponto de interferir de forma drástica no

RC: 105859

Disponível em: https://www.nucleodoconhecimento.com.br/lei/pornografia-infantil 
desenvolvimento psíquico infantil, provocando traumas irreversíveis e doenças transmissíveis por sexo.

Portanto, a pedofilia antes vista como prática aceita e recomendada, passou ao longo dos séculos a ser criminalizada pelas sociedades, ao passo que se notou os males que trazia para vítimas infantis. De modo resumido, até mesmo a tipificação penal necessitou acompanhar a evolução dessa prática, que passou a ser também no âmbito virtual.

\subsection{CONCEITO DE PEDOFILIA}

O jurista Ishida (2010, p. 505) define a pedofilia como sendo "uma psicopatologia ou desvio no desenvolvimento da sexualidade, caracterizado pela opção sexual por crianças e adolescentes de forma compulsiva e obsessiva".

Por sua vez, Nucci (2017, p. 107) conceitua a pedofilia dizendo:

A pedofilia é um distúrbio psicossexual, consistente em intenso desejo de manter práticas sexuais, reais ou fantasiosas, com crianças. É natural que, por extensão, possa-se entender como pedófilo, igualmente, aquele que se liga a adolescentes, em particular os mais novos, uma vez que a proteção legal se dá no mesmo diapasão.

O pedófilo é alguém doente que se utiliza da vulnerabilidade infantil para realização de seus desejos libidinosos. Ribeiro (2014, p. 1), em sua obra "Sem medo de falar: relato de uma vítima de pedofilia" destaca as formas de atuação e de aproximação que o portador da parafilia utiliza:

O pedófilo avança aos poucos, recua, avança com cuidado novamente. Vai estabelecendo seu território e seu comando com paciência. Em inglês, existe uma palavra para definir a estratégia de sedução do abusador de menores: grooming. Ela se refere a preparação e aos atos deliberados com o objetivo de se tornar alguém por quem a criança tem profunda admiração e em quem ela confia plenamente. O pedófilo se comporta como um protetor, um líder, uma fonte de inspiração. Ele cria um vínculo emocional, quebra as resistências naturais, vai se insinuando progressivamente.

RC: 105859

Disponível em: https://www.nucleodoconhecimento.com.br/lei/pornografia-infantil 
Diz ainda (2014, p. 1) "abusos sexuais são mais domésticos e rotineiros do que as pessoas imaginam e causam mais danos e traumas psicológicos do que as pessoas comumente pensam".

As pesquisadoras Libório e Sousa (2004, p. 75), por meio da Universidade Católica de Goiás, promoveram e organizaram com diversos coautores uma pesquisa para tratar da temática exploração sexual infantil e nesse sentido dizem: "A violência sexual perpetrada por adultos contra crianças ou adolescentes, por seu caráter íntimo e relacional, é particularmente grave, por ser "organizadora" de estruturas psíquicas e sociais, principalmente nos abusos sexuais de longa duração [...]".

Ora, o perfil do pedófilo está associado na maior parte das vezes às relações domésticas e aos familiares, sendo geralmente alguém próximo do círculo familiar que gradativa e sorrateiramente ganha confiança e espaço para cometer tais abusos.

\subsection{CASO HISTORIADO}

Marcelo Ribeiro (2014, p. 1), escritor do livro "Sem medo de falar: relato de uma vítima de pedofilia", reconta momentos aos quais foi submetido pelo maestro do coral que fazia parte. Diz:

[...] nesse horário a mãe do maestro também já tinha se recolhido para o quarto dela. Eu subia, fechava meu quarto fazendo de conta que tinha entrado e, sorrateiro, entrava no quarto do maestro. Era o momento em que ele pedia, definia, agia. Dizia palavras carinhosas, declarava seu amor em troca de sexo oral e depois me penetrava [...]. Eu saia do quarto e ia ao banheiro me lavar antes de dormir.

Ribeiro (2014, p. 1) em sua obra literária relata que "crianças alemãs foram atormentadas de forma sádica e abusadas sexualmente em um monastério católico na Bavária [...]".

RC: 105859

Disponível em: https://www.nucleodoconhecimento.com.br/lei/pornografia-infantil 
Embora o perfil pedófilo não tenha um formato definido, evidencia-se os inúmeros escândalos praticados pela Igreja Católica ao longo os séculos, inclusive em regiões americanas. Ribeiro $(2014$, p. 1) narra alguns desses episódios. In verbis:

O caso mais famoso foi o do fundador do movimento conservador mexicano Legionários de Cristo, Marciel Maciel, que cometeu abusos sexuais [...] O arcebispo de Nova York, cardeal Timothy Dylan, foi interrogado durante horas por advogados de quinhentas supostas vítimas de abusos que teriam sido cometidos por padres de Milwaukee entre 2002 e 2009 [...] Roger Mahony (dos Estados Unidos), Norberto Rivera Carrera (do México) e Sean Brady (da Irlanda) também tiveram seus nomes envolvidos em escândalos. Mahony [...] foi acusado de acobertar 129 casos de pedofilia nos EUA [...] Os casos se somam ao afastamento do ex-cardeal escocês Keith O'Brien, que admitiu sua má conduta sexual $[\ldots]$

Os relatos do escritor Marcelo Ribeiro demonstram o modos operandi dos portadores da parafilia, em épocas diferentes, cada qual utilizando dos meios e dos recursos disponíveis. Atualmente a pedofilia encontra na rede mundial de computadores, uma aliada, pois, embora a prática seja condenada socialmente, não é descoberta com facilidade.

\section{LIBERDADE SEXUAL E A INTERNET}

\subsection{PEDOFILIA, LIBERDADE SEXUAL INFANTIL E A INTERNET}

A Constituição da República Brasileira (1988, p. 1), também conhecida como Constituição Cidadã, reconhece a necessidade de proteção aos vulneráveis, trazendo para si, para a família e a sociedade em geral o dever da proteção integral aos mesmos, dispondo que:

Art. 227. É dever da família, da sociedade e do Estado assegurar à criança, ao adolescente e ao jovem, com absoluta prioridade, o direito à vida, à saúde, à alimentação, à educação, ao lazer, à profissionalização, à cultura, à dignidade, ao respeito, à liberdade e à convivência familiar e comunitária, além de colocá-los a salvo de toda forma de negligência, discriminação, exploração, violência, crueldade e opressão.

RC: 105859

Disponível em: https://www.nucleodoconhecimento.com.br/lei/pornografia-infantil 
Nesse diapasão, o ECA (1990, p. 1), em seu artigo 4º, caput, dispõe que:

É dever da família, da comunidade, da sociedade em geral e do poder público assegurar, com absoluta prioridade, a efetivação dos direitos referentes à vida, à saúde, à alimentação, à educação, ao esporte, ao lazer, à profissionalização, à cultura, à dignidade, ao respeito, à liberdade e à convivência familiar e comunitária.

A liberdade infantil está posta de forma genérica na CF e no ECA, sem diretamente se referirem a liberdade sexual, contudo consiste na "faculdade de livre escolha ou livre consentimento nas relações sexuais [...]" (FAYET, 2011, p. 1).

Sabe-se que a liberdade sexual infantil tem se sujeitado ao uso inadequado da internet. A web se desviou de sua função precípua, que é a de facilitar a vida das pessoas e globalizar o mundo, se tornando na verdade ferramenta para prática de vários crimes.

Nesse ínterim, o virtualismo facilita o acesso, a propagação e a produção de material pornográfico infantil, ocorrendo uma reação em cadeia, gerando agressões diretas e indiretas a esta garantia de suma importância que é o direito à liberdade, entre esta, a sexual.

A internet é um instrumento essencial para o sistema de globalização mundial, contudo os avanços tecnológicos são apressurados. Sua evolução rápida não permite que a disposição legislativa dos crimes cometidos no ambiente virtual a acompanhe.

Importante asseverar que o advento do Marco Civil da Internet (lei no 12.965/ 14 - MCI) trouxe benefícios à sociedade em geral. Em seu artigo 3으, o $\mathrm{MCl}(2014$, p. 1) traz os princípios norteadores da internet no Brasil:

Art. 3ำ A disciplina do uso da internet no Brasil tem os seguintes princípios:

I - Garantia da liberdade de expressão, comunicação e manifestação de pensamento, nos termos da Constituição Federal;

II - Proteção da privacidade;

RC: 105859

Disponível em: https://www.nucleodoconhecimento.com.br/lei/pornografia-infantil 
III - proteção dos dados pessoais, na forma da lei;

IV - Preservação e garantia da neutralidade de rede;

V - Preservação da estabilidade, segurança e funcionalidade da rede, por meio de medidas técnicas compatíveis com os padrões internacionais e pelo estímulo ao uso de boas práticas;

$\mathrm{VI}$ - Responsabilização dos agentes de acordo com suas atividades, nos termos da lei;

VII - preservação da natureza participativa da rede;

VIII - liberdade dos modelos de negócios promovidos na internet, desde que não conflitem com os demais princípios estabelecidos nesta Lei.

Parágrafo único. Os princípios expressos nesta Lei não excluem outros previstos no ordenamento jurídico pátrio relacionados à matéria ou nos tratados internacionais em que a República Federativa do Brasil seja parte.

Tendo em vista a punibilidade de divulgadores de material pornográfico infantil e sua penalização, a elaboração do Marco Civil da Internet (Lei 12.965/2014) demonstra ser um importante aliado no combate as ações delitivas digitais, mesmo tendo cunho cível.

Essa norma auxilia no procedimento de investigação de crimes virtuais, de forma que a web seja um ambiente menos hostil à atuação do Estado através da previsão de princípios, garantias, direitos e deveres para quem usa a rede, bem como, para a determinação de diretrizes.

\subsection{OBSTÁCULOS DE COMBATE NO ORDENAMENTO JURÍDICO BRASILEIRO}

A maior dificuldade jurídica e investigativa encontrada no combate aos crimes virtuais, está, conforme ligeiramente apontado, na constante inovação da internet, que cresce rapidamente, dificultando a atualização legislativa e o acesso a ferramentas tecnológicas capazes de identificar e combater tais delitos.

RC: 105859

Disponível em: https://www.nucleodoconhecimento.com.br/lei/pornografia-infantil 
Embora o $\mathrm{MCl}$ (lei oㅜ 12.965/14), tenha trazido vários benefícios à sociedade e ao ambiente virtual, ainda existem muitos desafios a serem superados no ordenamento jurídico brasileiro, que não conta com legislação penal específica para os crimes sexuais que ocorrem no âmbito virtual, ocorrendo tão somente o uso por equiparação das leis penais.

Cabe elencar alguns desafios pertinentes ao combate de crimes sexuais praticados nesse âmbito, como a proteção dos logs de acesso, legislação desatualizada, o Cloud Computing, integração global dos cibercriminosos, criptografia, estenografia e falta de interação entre os órgãos de investigação criminal (CANUTO, 2015, p. 1).

\subsection{COOPERAÇÃO INTERNACIONAL}

Para o combate eficaz da criminalidade virtual é necessário cooperação internacional, novas tecnologias e mecanismos inteligentes para que se transponha os obstáculos existentes no processo investigatório criminal. Deve-se levar em consideração que se tratando de ambientes virtuais não há fronteiras físicas.

No ano de 2017 foi deflagrado no Brasil uma operação, sob a coordenação do Ministério da Justiça, contra a pedofilia, a operação contou o apoio dos EUA, por meio de softwares e compartilhamento de arquivos. De acordo com o Ministro da Justiça, Torquato Jardim, os seis principais crimes do Brasil são transnacionais e assevera que "o complexo ambiente da internet e a ausência de fronteiras no mundo virtual, são elementos que propiciam terreno fértil à atuação desses criminosos" (FERRO, 2017, p. 1).

\section{A PORNOGRAFIA INFANTIL: ANÁLISE JURÍDICA E IMPLICAÇÕES}

\subsection{ANÁLISE DO TIPO PENAL}

O ECA, a partir do artigo 228, lista os tipos penais cometidos contra crianças e adolescentes, contudo, é no artigo 240 e seguintes que o Estatuto trás em espécie os

RC: 105859

Disponível em: https://www.nucleodoconhecimento.com.br/lei/pornografia-infantil 
delitos sexuais cometidos contra os vulneráveis. Interessa-nos falar especificamente do artigo 241-A, que dispõe acerca da legislação que envolve a pornografia infantil. Nesse sentido dispõe o ECA (1990, p. 1):

Art. 241-A. Oferecer, trocar, disponibilizar, transmitir, distribuir, publicar ou divulgar por qualquer meio, inclusive por meio de sistema de informática ou telemático, fotografia, vídeo ou outro registro que contenha cena de sexo explícito ou pornográfica envolvendo criança ou adolescente.

Pena - reclusão, de 3 (três) a 6 (seis) anos, e multa.

Tavares (2006, p. 229) esclarece que a divulgação e a publicação de que trata o artigo 241-A do ECA poderá ser realizada por diversos meios, pois é um tipo penal com núcleo plural, não trazendo o referido um rol taxativo e sim exemplificativo. Nesse sentido:

Divulgar ou publicar [...] utilizando qualquer meio de comunicação oral ou escrita, de viva voz ou através de rádio, televisão, vídeo e filmes, computadores e o sistema de internet ou outro recurso tecnológico que vier a ser posto nos meios de comunicação de massa.

Destaca-se que no ano de 2008, foi promovida uma minirreforma no ECA, alteração esta que englobou o artigo em estudo (241-A), trazendo mudanças importantes para o combate da pornografia infantil. A lei 11829/2008 alterou os artigos 240 e 241 e criou os artigos 241-A, 242-B, 243-C, 244-D e 245-E.

Del-Campo e Oliveira (2009, p. 361) esclarecem os termos do artigo 241-A do ECA, informando que embora a internet tenha sido abarcada pela reforma promovida pela lei supramencionada, foi tímida ao não prever o agravamento da pena na situação específica do modos operandi ambiente virtual. In verbis:

Embora a internet não tenha sido destacada pelo legislador, ficando englobada no conceito de sistema telemático, em razão do elevado número de páginas dedicadas a pedofilia que contém, pela facilidade com que as informações podem ser divulgadas e pelo dano potencial consistente na amplitude da propagação, deveria ter recebido tratamento especial, com pena agravada.

RC: 105859

Disponível em: https://www.nucleodoconhecimento.com.br/lei/pornografia-infantil 
A lei prevê como penalidade para os crimes cometidos no artigo 241-A, reclusão, de 3 (três) a 6 (seis) anos, e multa. Assim, o legislador dispôs a pena em abstrato com pouca abrangência.

Moraes (2018, p. 1), jurista e delegado da Polícia de Belo Horizonte MG, faz alusão a pornografia infantil virtual brasileira, dizendo que:

\begin{abstract}
Não têm sido poucos os casos de flagrante por posse de pornografia infantil - com investigados que confessam serem ávidos "consumidores" daquele material ilícito e que possuem grandes quantidades de arquivos armazenados em seus computadores ou mídias - que terminam com o arbitramento de fiança, restituindo imediatamente à liberdade e ao convívio social pessoas com grande potencial lesivo à dignidade infanto-juvenil.
\end{abstract}

Por vezes o artigo 241-A é confundido com o artigo 241-B do ECA, que dispõe que "adquirir, possuir ou armazenar, por qualquer meio, fotografia, vídeo ou outra forma de registro que contenha cena de sexo explícito ou pornográfica envolvendo criança ou adolescente" terá como pena a reclusão, de 1 (um) a 4 (quatro) anos, e multa.

Sendo assim, é comum no ordenamento jurídico brasileiro que o artigo 241-A seja desclassificado para o delito ao artigo 241-B (ocorre o semelhante ao uso e o tráfico de drogas). De modo simples, o artigo 241-A é dedicado aos agressores que de alguma forma veiculam o material pornográfico infantil, enquanto o artigo 241-B se dedica a quem consome o material pornográfico produzido.

\title{
4.2 DIMENSIONAMENTO DA PORNOGRAFIA INFANTIL VIRTUAL
}

A pornografia infantil além de um problema social e criminal. Delmanto et. al. (2016, p. 1) expõe que "as crianças e adolescentes têm sofrido violências sexuais de toda a sorte, crescendo inclusive pela internet, os casos de pedofilia".

Segundo Londero (2016, p. 1) a pornografia "inclui qualquer descrição ou representação pictórica do corpo humano que indica aquelas partes que são normalmente mantidas cobertas uma resposta erótica".

RC: 105859

Disponível em: https://www.nucleodoconhecimento.com.br/lei/pornografia-infantil 
Segundo a ONG Safernet, no Brasil, a pornografia infantil é o crime virtual mais comum, somente no ano de 2013, 24.993 (vinte e quatro mil novecentos e noventa e três) páginas foram denunciadas às autoridades por conter material envolvendo pornografia infantil, representando um aumento de 3,83\% em comparação a 2012 (CAPUTO, 2014).

\subsection{MEIOS JURÍDICOS DE COMBATE A PEDOFILIA VIRTUAL}

Embora a pedofilia seja considerada doença (CID 10 F65.4), Silva (2014, p. 1), incumbe destacar que "a maioria dos crimes envolvendo atos sexuais contra crianças são realizados por pessoas que não são consideradas clinicamente pedófilas, já que não sentem atração sexual por crianças". No geral os criminosos têm plena consciência dos atos que cometem, não sendo necessariamente pedófilos.

Projetos de lei já tramitam no congresso, contudo o processo é moroso e devido às grandes mudanças existentes na internet, os meios de regulamentar concretamente se tornam difíceis. Surge, assim, a necessidade de uma normatização ágil para o combate efetivo das práticas delituosas efetuadas na rede mundial de computadores.

Destaca-se o projeto de lei 1776/2015, tipifica o crime de Pedofilia como hediondo e propõe agravante de um terço

para o criminoso que distribuir, publicar, armazenar ou divulgar imagem de menores por meio de montagem fotográfica ou vídeo na chamada deep web, zona da internet que garante privacidade e anonimato aos navegantes. A pena pode chegar a até 13 anos e 4 meses de reclusão e multa (MENDES, 2021, p. 1).

Faz-se necessária a legalização para combater estas práticas (divulgação de material pornográfico na rede) que se firmam cada vez mais em território nacional. Brito (2013, p. 1) informa que:

A luta contra a pedofilia e a pornografia infantil na internet requer uma coalizão de forças envolvendo crianças, indústria, formuladores de políticas, educadores e pais assegurar que os usuários estejam

RC: 105859

Disponível em: https://www.nucleodoconhecimento.com.br/lei/pornografia-infantil 
conscientes dos riscos potenciais e tenham disponíveis os meios necessários para combater riscos.

Além do mais, deve-se cobrar do poder público maiores investimentos na compra de equipamentos tecnológicos sensíveis e adequados para o uso nos procedimentos investigatórios e ainda, na formação de delegacias e recursos humanos preparados para combater esse tipo de prática especificamente.

\section{CONSIDERAÇÕES FINAIS}

Após os estudos e desafios apresentados, é necessária a implementação de medidas sérias, integradas e assertivas, com o intuito de coibir e punir adequadamente as práticas delitivas (consumo ou produção de pornografia infantil). São medidas em respostas a questão norteadora:

a) A desativação de sites pornográficos infantis já existentes, impedindo o acesso de conteúdo inadequado a outros agressores;

b) A rápida atualização legislativa que tipifique e complete as lacunas legais existentes por causa da rápida evolução da internet;

c) A formação de equipes especializadas e grupos de investigação específicos, além de profissionais de $\mathrm{Tl}$;

d) A criação e a instalação de Delegacias de Polícia Especializadas no Atendimento de Crianças e Adolescentes vítimas de crimes sexuais virtuais;

e) A cooperação internacional para o compartilhamento mútuo de tecnologias de ponta eficazes aos procedimentos investigatórios.

Tudo isso será capaz de gerar um microssistema eficaz de proteção para combate e repressão a pornografia infantil no ambiente virtual, diminuindo progressivamente sua impunibilidade.

RC: 105859

Disponível em: https://www.nucleodoconhecimento.com.br/lei/pornografia-infantil 


\section{REFERÊNCIAS}

BRASIL. Constituição (1988). Da família, da criança, do adolescente, do jovem e do idoso: da criança e do adolescente. 1988. Disponível em: <http://www.planalto.gov.br/ccivil_03/constituicao/constituicao.htm>. Acesso em: 21 maio 2018.

BRASIL. Lei n. 8.069, de 13 de julho de 1990. Estatuto da Criança e do Adolescente. Título I: Das Disposições Preliminares. 1990. Disponível em: <http://www.planalto.gov.br/ccivil_03/leis//8069.htm>. Acesso em: 21 abr. 2018.

BRASIL. Lei do Marco Civil. Lei no 2.965/ 2014. Brasília, DF: Casa Civil, Subchefia para Assuntos Jurídicos, 2014. Disponível em: <http://www.planalto.gov.br/>. Acesso em: 12 mar. 2018.

BRASIL. Constituição (1988). Da família, da criança, do adolescente, do jovem e do idoso: da criança e do adolescente. 1988. Disponível em: <http://www.planalto.gov.br/ccivil_03/constituicao/constituicao.htm>. Acesso em: 21 maio 2018.

BRITO, Auriney. Direito penal informático. São Paulo: Saraiva, 2013.

CANUTO, Luiz Cláudio. Agência Câmara de Notícias. CPI constata dificuldade em rastrear e punir crimes de internet. 2015. Disponível em: $<$ https://www.camara.leg.br/noticias/467819-cpi-constata-dificuldade-em-rastrear-epunir-crimes-de-internet/>.Acesso em: 30 de dez. 2021.

CAPUTO, Victor. Pornografia infantil é o crime virtual mais comum no Brasil: Levantamento da ONG Safernet mostra que pornografia infantil representou quase metade das páginas denunciadas à Polícia Federal. 2014. Disponível em: $<$ https://exame.abril.com.br/tecnologia/pornografia-infantil-e-o-crime-virtual-maiscomum-no-brasil/>. Acesso em: 14 set. 2018. 
DEL-CAMPO, Eduardo Roberto Alcântara; OLIVEIRA, Thales Cezar de. Estatuto da criança e do adolescente. 6ª ed. São Paulo: Atlas, 2009.

DELMANTO, Celso et al. Código penal comentado. 9. ed. São Paulo: Saraiva, 2016. FAYET, Fabio Agne. O delito do estupro. Porto Alegre: Livraria do Advogado, 2011. FERRO, Maurício. Ministro da Justiça destaca cooperação internacional em operação de combate à pedofilia: Torquato Jardim afirmou que seis maiores crimes são transnacionais. 2017. Disponível em: <https://oglobo.globo.com/brasil/ministro-da-justica-destaca-cooperacaointernacional-em-operacao-de-combate-pedofilia-21972177>. Acesso em: 13 set. 2018.

HISGAIL, Fani. Pedofilia: um estudo psicanalítico. São Paulo: Iluminuras, 2007.

ISHIDA, Valter Kenji. Estatuto da criança e do adolescente: doutrina e jurisprudência. 12. Ed. São Paulo: Atlas, 2010.

LENZA, Pedro. Direito constitucional esquematizado. 21 ed. São Paulo: Saraiva, 2017.

LIBÓRIO, Renata Maria Coimbra; SOUSA, Sônia M. Gomes. Org. A exploração sexual de crianças e adolescentes no Brasil: reflexões teóricas, relatos de pesquisas e intervenções psicossociais. São Paulo: Casa do Psicólogo, 2004; Goiânia, GO, Universidade Católica de Goiás, 2004.

LONDERO, Rodolfo Rorão. Pornografia e censura: livro eletrônico. Londrina: Eduel, 2016.

LOUREIRO, Antonio José Cacheado; SILVA, Amanda Cristina Ferreira da. Concepções de Infância ao Longo da História e a Evolução Jurídica do Direito da Criança. Boletim Jurídico, Uberaba/MG, a. 30, no 1605. Disponível em 
https://www.boletimjuridico.com.br/artigos/direito-da-infancia-ejuventude/4326/concepcoes-infancia-ao-longo-historia-evolucao-juridica-direitocrianca. Acesso em 30 dez. 2019

MENDES. Priscila. 2021. R7. Câmara aprova projeto de lei que torna pedofilia crime hediondo. Disponível em: <https://noticias.r7.com/brasilia/camara-aprovaprojeto-de-lei-que-torna-pedofilia-crime-hediondo-18112021>. Acesso em: $30 \mathrm{dez}$. 2021.

MORAES, Elster Lamoia de. Pornografia infantil: necessidade de majoração das penas cominadas a alguns crimes previstos no Estatuto da Criança e do Adolescente. Revista Jus Navigandi, ISSN 1518-4862, Teresina, ano 18, n. 3740, 27 set. 2013. Disponível em: <https://jus.com.br/artigos/25418>. Acesso em: 15 mar. 2018.

$\mathrm{NUCCl}$, Guilherme de Souza. Leis penais e processuais penais comentadas. 10 ed. ver., atual. e ampl. vol. 2. Rio de Janeiro: Forense, 2017.

RIBEIRO, Marcelo. Sem medo de falar: Relato de uma vítima da Pedofilia. $1^{\underline{a}}$ ed. São Paulo: Paralela, 2014. E-book.

SILVA, Lillian Ponchio. Pedofilia e abuso sexual de crianças e adolescentes; Coordenadores Alice Bianchini, Ivan Luís Marques e Luiz Flávio Gomes. São Paulo: Saraiva, 2013.

TAVARES, José de Farias. Comentários ao Estatuto da Criança e do Adolescente. Rio de Janeiro: Editora Forense, 2006.

Enviado: Novembro, 2021.

Aprovado: Janeiro, 2022. 